Document downloaded from:

http://hdl.handle.net/10251/121368

This paper must be cited as:

Belenguer Martínez, A.; Fernández-Berlanga, MD.; Ballesteros, JA.; De Dios, JJ.; Esteban González, H.; Boria Esbert, VE. (2018). Compact Multilayer Filter in Empty Substrate Integrated Waveguide With Transmission Zeros. IEEE Transactions on Microwave Theory and Techniques. 66(6):2993-3000. https://doi.org/10.1109/TMTT.2018.2823306

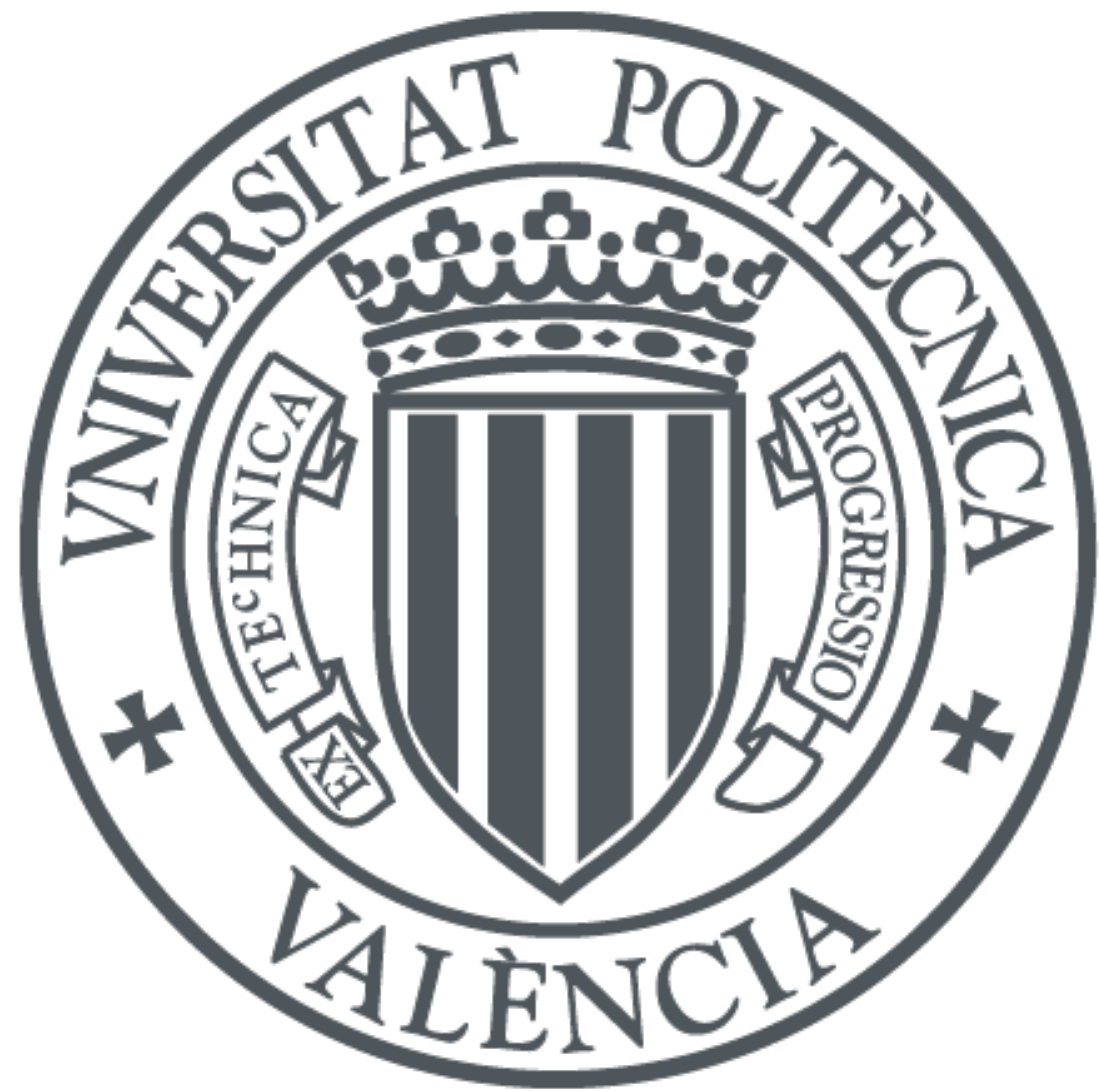

The final publication is available at

http://doi.org/10.1109/TMTT.2018.2823306

Copyright Institute of Electrical and Electronics Engineers

Additional Information 


\title{
Compact Multilayer Filter in Empty Substrate Integrated Waveguide with Transmission Zeros
}

\author{
Angel Belenguer, Senior Member, IEEE, Marcos D. Fernandez, José A. Ballesteros, Juan J. de Dios, \\ Hector Esteban, Senior Member, IEEE, and Vicente E. Boria, Senior Member, IEEE
}

\begin{abstract}
Empty Substrate Integrated Waveguide has recently received special attention due to the fact that by removing the dielectric, this technology not only maintains the advantages of Substrate Integrated Waveguide circuits, but also improves their behaviour. Many circuits have been designed for Empty Substrate Integrated Waveguide, with several filters of different performance among them. The next challenge is to achieve the maximum possible compactness degree for these circuits. In this paper, we present the design of a multilayer Empty Substrate Integrated filter with the same performance as if it were manufactured in a single layer, but significantly increasing its compactness and mechanical resistance.
\end{abstract}

Index Terms-Empty substrate integrated waveguide, ESIW, substrate integrated waveguide, SIW, substrate integrated circuit, SIC, compact bandpass filter, high quality factor, multilayer.

\section{INTRODUCTION}

$\mathbf{S}$ INCE 2014, several alternatives have arisen to reduce losses in devices based on Substrate Integrated Waveguides (SIWs) [1]. Nowadays, the most promising alternatives are the ones that intend the reduction of those losses by eliminating the dielectric substrate. That can be achieved by emptying the waveguide and then enclosing it with two metallic covers, as it was firstly suggested in [2] by using Empty Substrate Integrated Waveguide (ESIW), and later in [3] with Air-filled Substrate Integrated Waveguide.

These technologies keep the characteristics of Substrate Integrated Waveguide (SIW) [1] regarding low cost, manufacture easiness, reduced size and integration with other circuits within the same substrate. Additionally, the behaviour of these circuits (especially in terms of losses) is improved as the dielectric substrate is removed.

Since the proposition of the ESIW [2], different devices have been designed based on this technology; among them there are filters with high quality factor, either linear [2] or folded [4], couplers [5], [6], antennas [7] or a thru-reflect-line calibration kit [8]. All of them have in common that they are single-layer devices.

This work was supported by the Ministerio de Economía y Competitividad, Spanish Goverment, under Research Projects TEC2016-75934-C4-3-R and TEC2016-75934-C4-1-R.

A. Belenguer, M. D. Fernandez, J. A. Ballesteros, and J. J. de Dios are with Departamento de Ingeniería Eléctrica, Electrónica, Automática y Comunicaciones, Universidad de Castilla-La Mancha, Escuela Politécnica de Cuenca, Campus Universitario, 16071 Cuenca, Spain (e-mail: angel.belenguer@uclm.es)

H. Esteban and V. E. Boria are with Departamento de Comunicaciones, Universitat Politècnica de València, 46022 Valencia, Spain (e-mail: hesteban@dcom.upv.es).
Multilayer devices are commonly used in PCB for electronic equipment to reduce weight and volume. Multilayering is achieved by stacking two or more interconnected layers. The resulting structures are very compact and can be manufactured easily according to standard PCB procedures.

Several multilayer devices in SIW can also be found. A good revision of them is stated in [9], including filters [10], [11], couplers [12], power dividers [13]-[16], phase shifters [17] or antenna arrays [18]. The main advantage of all of them is their high degree of compactness.

As it has been formerly stated, the features of ESIW devices are better due to the absence of dielectric. The necessity of compactness is a topic very interesting in ESIW, given that the absence of dielectric permits a drastic increase of the quality factor of the devices, but their size is always greater than the size of equivalent SIW devices. Then, and having into account the advantages of multilayer devices, it will be of great interest the combination of a high degree of compactness with the good features of ESIW devices. Up to date, the only ESIW multilayer designs available are two transitions. The first of them allows the transition between two ESIW circuits in contiguous layers [19]. The second one permits transition among an arbitrary number of layers [20]. These transitions are fundamental for being able to design multilayer ESIW circuits, as they may interconnect the necessary layers in the circuits.

This paper proposes the design of a multilayer filter in ESIW. Compactness is achieved by stacking the resonators, which are implemented in consecutive layers of the structure. In this way, the high quality factors of ESIW devices are maintained and, at the same time, an important compactness increase is reached.

The paper is structured as follows: in section II the filter structure is explained, section III shows the design procedure, section IV includes the simulations carried out to validate the designs, section $\mathrm{V}$ is devoted to the manufacture of the prototype and the measured results and, finally, section VI presents the final conclusions.

\section{FILTER STRUCTURE}

\section{A. Filter elements}

This filter presents a traditional structure. A set of series resonators are coupled through elements with appropriate characteristics that act as impedance inverters (Fig. 1).

In this case, resonators are built through empty ESIW guides, so the filters will have high quality factors, given that 


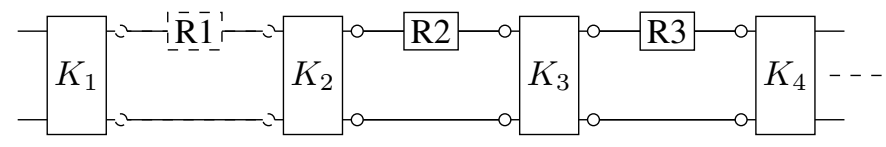

Fig. 1. Block diagram of a traditional inverter-based filter.

this kind of integrated waveguides have very low losses. To achieve the desired compactness, so that the resonators could be grouped in a stack, inverters are implemented with E-plane bends of $180^{\circ}$ (U-bends), as Fig. 2 shows. There, $b$ is the total height of the ESIW ( $a$, the waveguide width, would be perpendicular to the plane of the figure), $g_{r}$ is the total height of the layer that separates two consecutive resonators within the stack and $w_{\text {bend }}$ is the total length of the bend. $w_{\text {bend }}$ is the parameter that would allow the control of the inversion constant of the bend, or what is equivalent, the coupling level between the resonators interconnected by the bend.

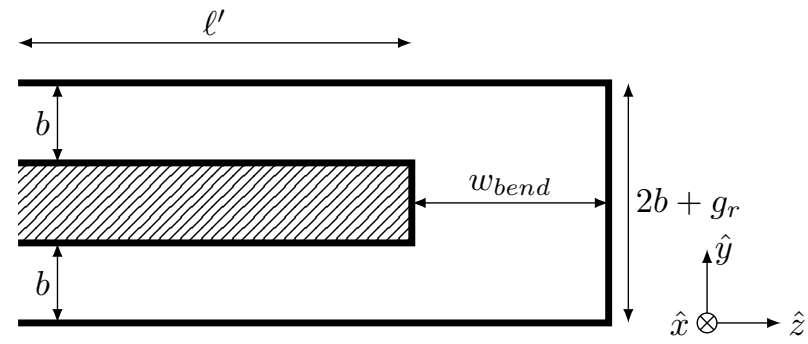

Fig. 2. U-bend that couples contiguous resonators in this filter topology (E-plane cross-section).

Finally, Fig. 3 illustrates the cross-section of a 5-cavities filter like the one that will be presented in the Results section. Given that structure of the filter, where the resonators are stacked up, the input and output ports are at different levels. It should not be a problem if the aim is just the manufacture of a stand-alone filter, but it can be very problematic if it is expected the integration of such compact filter in a complete system based on ESIW.

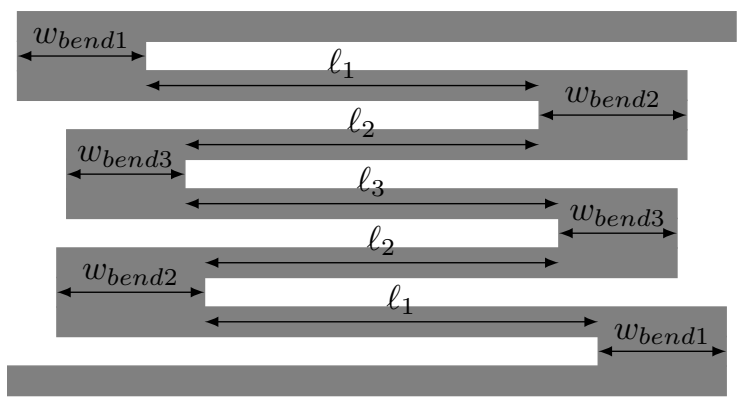

Fig. 3. Longitudinal cut of the novel compact ESIW filter.

\section{B. Interlevel transition}

A filter with the input and output ports at the same level can be achieved by using the multilayer transition of [20] that interconnects ESIWs separated an arbitrary number of levels.
Fig. 4(a) shows a longitudinal cut of such multilayer transition, whereas Fig.4(b) reveals the shape of a 5th-order filter where that transition is used to implement the output at the same level as the input.

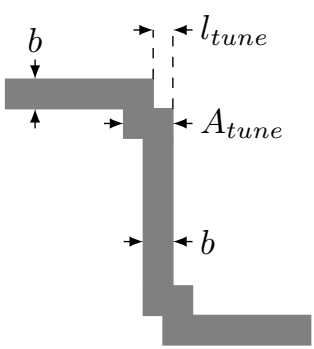

(a)

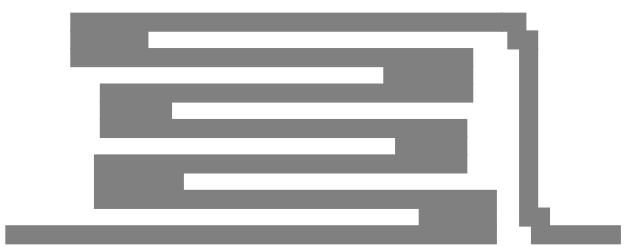

(b)

Fig. 4. (a) Detailed view of the multilayer transition of [20]. (b) Longitudinal cut of the novel compact ESIW filter with input and output in the same layer.

As it is stated in [20], the multilayer transition has an excellent performance and does not affect the filter response. Consequently, the synthesis of the filter will be always referenced to that in Fig. 3, with output and inputs ports located at different levels.

\section{DESIGN METHOD}

As mentioned in the former section, this filter can be analysed as a traditional filter made up of the cascade connection of inverters and resonators. Therefore, the filter design process has two parts: the first deals with the calculation of the length of the bends, i.e. $w_{\text {bend } i}$, to obtain the inversion constants of the prototype (Fig. 1); whereas the second part must determine the proper length of the waveguides that build the resonators, i.e $\ell_{i}$, so that they might compensate the phase error introduced by the bends in comparison with the phase of an ideal inverter

But first, in order to design the filter, it is necessary to calculate the value of the inverter constants. Assuming that all the resonators are identical, according to [21], the following expressions can be applied to find their values,

$$
K_{1}=\sqrt{\frac{X F_{B}}{g_{0} g_{1}}} ; K_{j}=\frac{X F_{B}}{\sqrt{g_{j-1} g_{j}}} ; K_{N+1}=\sqrt{\frac{X F_{B}}{g_{N} g_{N+1}}}
$$

where: $N$ is the order of the filter, $F_{B}$ is the fractional bandwidth of the filter, $X$ is the reactance slope parameter of the resonators, and $g_{i}$ are the values of the elements of the lowpass filter prototype.

If the resonators of a given filter are implemented with uniform pieces of waveguide of length equal to $\lambda_{g} / 2$, then $X=\pi / 2 . X=\pi$ for resonators of length $\lambda_{g}$, etc. However, although it would not appear to be the case, the resonators 
of the compact filter of this paper are not uniform pieces of waveguide. The inverters of the filter presented in this paper, U-bends of Fig. 3, are connected using straight pieces of waveguide, but these inverters, as it will be demonstrated in the following sections, present a non-negligible length, in fact around $\lambda_{g} / 4$, so that they contribute to the resonance. As a result, these composite resonators present a different slope factor. From simulations, it has been calculated that the reactance slope factor for these non-uniform resonators is approximately $X=2 \pi / 3$, if a waveguide of length close to $\lambda_{g} / 2$ is used to connect consecutive inverters.

\section{A. Determining the length of the bends}

The procedure to determine the length of each bend is quite simple. Given an impedance inverter with normalized inversion constant $K_{i}$, which is accessed through lines or waveguides of impedance normalized to unity, the amplitudes of the scattering parameters are:

$$
\left|S_{11}\right|=\left|\frac{K_{i}^{2}-1}{K_{i}^{2}+1}\right| ;\left|S_{21}\right|=\sqrt{1-\left|\frac{K_{i}^{2}-1}{K_{i}^{2}+1}\right|^{2}}
$$

To obtain the length of the bend, the value of $w_{\text {bend } i}$ is optimized so that the module of $S_{21}$ (or $S_{11}$ ) could be the closest possible to its ideal value, given by (2). As this is a one-variable optimization process, it converges very fast and all tested algorithms give good results. A general purpose software for electromagnetic analysis can be used to analyse the bend (for instance, CST Studio Suite 2014 is the one used in this paper).

There is an important detail to consider in the response of this kind of inverter; for that, a specific bend will be analysed to illustrate that characteristic. The bend is built up using substrates of $h_{c}=0.813 \mathrm{~mm}$ height and met $=26.5$ microns of metallization (addition of the original and galvanic metallizations). The thickness of the tin solder paste layer used to join the layers forming the bend is estimated in met $_{\text {tin }}=5 \mathrm{mi}-$ crons. With these data: $b=h_{c}+2 m e t+2$ met $_{t i n}=0.876 \mathrm{~mm}$ and $g_{r}=h_{c}+2 m e t=0.866 \mathrm{~mm}$. Finally, a waveguide width of $a=15.7988 \mathrm{~mm}$ has been chosen for this bend; therefore, this ESIW will work in the Ku-band.

Fig. 5 shows the response of the inverter at $15 \mathrm{GHz}$ for different values of the length of the bend. The normalized inversion coefficient for this bend has been represented, as well as the transmission coefficient of the bend $\left(S_{21}\right)$. When this bend has an approximate length of $7.41 \mathrm{~mm}$, the response has a transmission zero. That null is produced when the length of the bend is close to $\lambda_{g} / 4$ and, in such case, the guides feeding the bend arrive at an open-circuit, as the bend is simply a guide of height $2 b+g_{r}$ ended in a short-circuit, as Fig. 2 shows. Besides, the response reveals another important characteristic. The required inversion constant can be achieved by two different values of length. The first solution is underneath the length that produces the transmission null, whereas the second one is above that length. If the first solution is taken in the design, the transmission zero will be achieved for higher electrical lengths of the inverters, that is, at frequencies below the design frequency and then, below the passband. Regarding

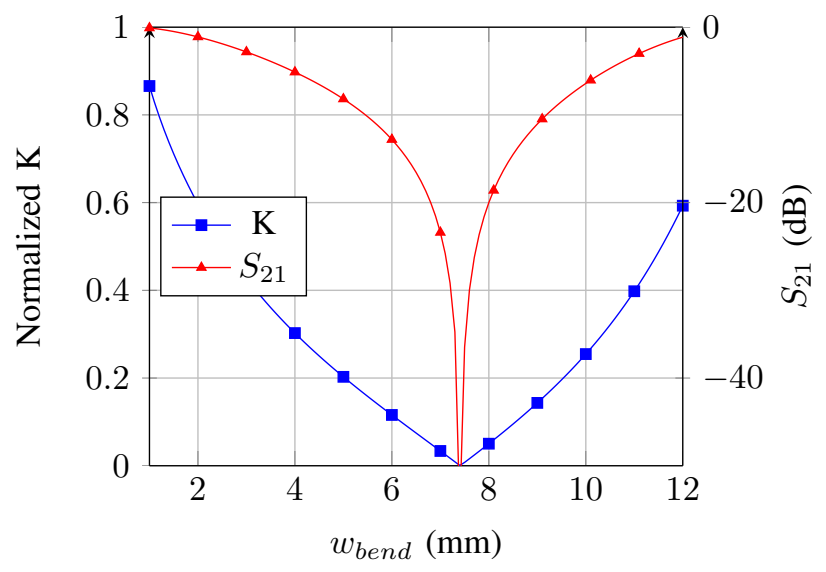

Fig. 5. Parametric response at $15 \mathrm{GHz}$ of a $\mathrm{Ku}$ band U-bend (inverter) in terms of its length $w_{\text {bend }}$.

the second solution, the transmission zero will be achieved for lesser electrical lengths of the inverters, that is, above the passband. For instance, for the 5th-order filter of Fig. 4, the first solution can be taken for inverters 1, 3, 4 and 6, hence, a pair of double-zeros are introduced (given the filter symmetry) at frequencies below the passband of the filter. If the second solution is adopted for inverters 2 and 5, a double-zero will be placed above the passband. Therefore, this procedure gives a response much more selective than that given, for instance, if the first solution should be always chosen for all the inverters.

\section{B. Determining the lengths of the resonators}

The lengths of the resonators must correct the phase-loading effect caused by the practical implementation of the inverters. To determine that correction, each bend is fed at the input and output ports with a waveguide of length $\lambda_{g} / 4$. The bend is analysed with a simulator (CST Studio Suite 2014 in this specific case) to obtain the phase of parameter $S_{11}, \operatorname{Ph}\left(S_{11}\right)$, in the interval $[0,2 \pi]$. The objective is deriving the length of the input lines that makes possible that $\operatorname{Ph}\left(S_{11}\right)$ fits exactly $\pi$ radians:

$$
\ell^{\prime}=\lambda_{g} / 4+\frac{P h\left(S_{11}\right)-\pi}{2 \beta}
$$

where $\beta$ is the phase constant of the guides feeding the bend.

The previous length is calculated for all the bends, $\ell_{i}^{\prime}$. Once obtained those values, the length of the resonators is calculated as:

$$
\ell_{i}=\ell_{i}^{\prime}+\ell_{i+1}^{\prime}
$$

Although a pair of inverters are connected through a piece of waveguide of length approximately equal to $\lambda_{g} / 2$, a firstorder simple resonator is not obtained, because each inverter incorporates a guide of an approximate length of $\lambda_{g} / 4$ that does contribute to resonance. As a result, this structure actually provides a second-order resonator of length $\lambda_{g}$, given that it incorporates the additional $2 \lambda_{g} / 4$ provided by the surrounding inverters.

To implement a filter with first-order resonators, the lengths are:

$$
\ell_{i}=\ell_{i}^{\prime}+\ell_{i+1}^{\prime}-\lambda_{g} / 2
$$


TABLE I

VALUES OF THE DESIGNED FILTERS.

\begin{tabular}{|l|c|c|c|c|c|c|c|c|}
\hline & \multicolumn{4}{|c|}{ Initial Values (mm) } & \multicolumn{4}{c|}{ Optimized Values (mm) } \\
\hline$f_{c}(\mathrm{GHz}) /$ Order & $\mathbf{1 1} / \mathbf{7}$ & $\mathbf{1 5} / \mathbf{5}$ & $\mathbf{3 5} / \mathbf{3}$ & $\mathbf{3 5} / \mathbf{7}$ & $\mathbf{1 1} / \mathbf{7}$ & $\mathbf{1 5} / \mathbf{5}$ & $\mathbf{3 5} / \mathbf{3}$ & $\mathbf{3 5} / \mathbf{7}$ \\
\hline$l_{1}$ & 16.7235 & 12.4550 & 4.3672 & 4.3701 & 16.5299 & 12.6191 & 4.2817 & 4.2932 \\
\hline$l_{2}$ & 18.1478 & 11.2910 & 5.1589 & 4.7906 & 18.1806 & 11.2767 & 5.1093 & 4.8064 \\
\hline$l_{3}$ & 18.0103 & 12.0223 & - & 4.7413 & 18.0152 & 11.8925 & - & 4.7448 \\
\hline$l_{4}$ & 18.6261 & - & - & 4.9948 & 18.4844 & - & - & 4.9378 \\
\hline$W_{\text {bend } 1}$ & 15.1539 & 3.4088 & 4.4676 & 4.4024 & 15.3260 & 3.3497 & 4.5465 & 4.4722 \\
\hline$W_{\text {bend } 2}$ & 9.4081 & 8.6137 & 2.4748 & 2.5716 & 9.3239 & 8.6711 & 2.4137 & 2.5233 \\
\hline$W_{\text {bend } 3}$ & 11.6337 & 6.5213 & - & 3.4490 & 11.6444 & 6.5094 & - & 3.4575 \\
\hline$W_{\text {bend } 4}$ & 9.8186 & - & - & 2.7180 & 9.8177 & - & - & 2.7162 \\
\hline
\end{tabular}

Since $\ell_{i}^{\prime}$ and $\ell_{i+1}^{\prime}$ are close to $\lambda_{g} / 4$, these lengths are very small (even negative). As a matter of fact, the filter with first-order resonators using this topology is not feasible, and this is the reason why resonators of length $\lambda_{g}$ (second-order resonators) have been used. The filter will increase in volume and the compactness will be less, but higher quality factors will be achieved, since they will be able to store a larger amount of energy.

Even so, if this filter is compared to a traditional in-line filter, a high degree of compactness is obtained. For instance, a 5th-order filter, according to this compact multilayer topology, presents an approximate length of $\lambda_{g}$, whereas the equivalent in-line filter with first-order resonators would have an approximate length of $2.5 \lambda_{g}$ (2.5 times longer). On the other hand, an in-line filter with a similar quality factor than that of the compact filter, would have an approximate length of $5 \lambda_{g}$ (5 times longer).

\section{Complete optimization}

Once determined the initial dimensions of the filter, a full wave simulation is started in order to optimize all the design parameters (lengths of inverters and resonators) to obtain a response as close as possible to that of the prototype. For this optimization, a Nelder Mead Simplex algorithm is used. The goal of the optimization is to minimize the sum of the squared differences between the scattering parameters of the designed filter and the same parameters of the filter prototype. Specifically, the sum of the squared differences of $S_{21}$ parameters is calculated in two different intervals: from $f_{c 1}-f_{c} F_{B}$ to $f_{c 1}$, and from $f_{c 2}$ to $f_{c 2}+f_{c} F_{B}$, being $f_{c}$ the central frequency, $f_{c 1}$ and $f_{c 2}$ the cutoff frequencies, and $F_{B}$ the fractional bandwidth of the filter. The sum of the squared differences of $S_{11}$ parameters is calculated from $f_{c 1}$ to $f_{c 2}$. Lastly, all this values are added to obtain the final value of the cost function to minimize.

\section{APPLICATION OF THE DESIGN METHOD}

Several Chebyshev filters, with different characteristics, have been designed to validate the design procedure stated in the former section. Specifically, the following filters are considered:

- 7th-order filter at $11 \mathrm{GHz}$ with a fractional bandwidth of $2 \%$ and $0.05 \mathrm{~dB}$ ripple, built with Rogers $4003 \mathrm{C}$ of $0.813 \mathrm{~mm}, 26.5$ microns of metallization (original plus galvanic) and soldering layers of 5 microns thickness.

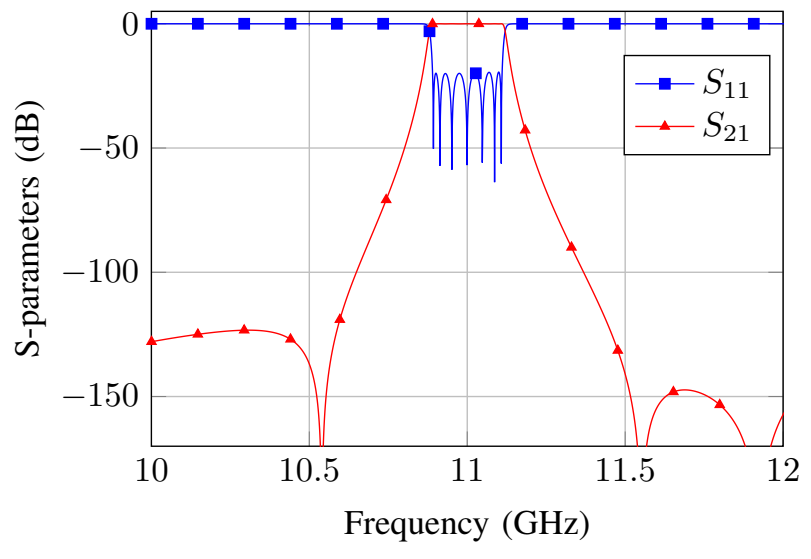

Fig. 6. Simulation results for the $11 \mathrm{GHz}$ filter.

- 5th-order filter at $15 \mathrm{GHz}$ with a fractional bandwidth of $3 \%$ and $0.01 \mathrm{~dB}$ ripple, built with Rogers $4003 \mathrm{C}$ of $0.813 \mathrm{~mm}, 26.5$ microns of metallization (original plus galvanic) and soldering layers of 5 microns thickness.

- 3rd-order filter at $35 \mathrm{GHz}$ with a fractional bandwidth of $4 \%$ and $0.1 \mathrm{~dB}$ ripple, built with Rogers $4003 \mathrm{C}$ of $0.305 \mathrm{~mm}, 26.5$ microns of metallization (original plus galvanic) and soldering layers of 5 microns thickness.

- 7th-order filter at $35 \mathrm{GHz}$ with a fractional bandwidth of $4 \%$ and $0.1 \mathrm{~dB}$ ripple, built with Rogers $4003 \mathrm{C}$ of $0.305 \mathrm{~mm}, 26.5$ microns of metallization (original plus galvanic) and soldering layers of 5 microns thickness.

Initial and optimized values for the lengths of resonators and inverters are shown in table I. Only the values for the first half of the filter are indicated, as all the designed filters are symmetrical.

Figures 6 to 9 show the ideal response of each one the designed filters, but considering neither the multilayer transition, nor the microstrip-to-ESIW transition or possible losses, being the observed behaviour rather well. Simulation results validate the design procedure stated in this paper, proving its high versatility for designing filters at different frequencies, on different substrates, with different orders and ripple levels.

\section{REsults}

Once validated the design procedure, a 5th order Chevyshev filter has been manufactured that works at $15 \mathrm{GHz}$, with a fractional bandwidth of $3 \%\left(f_{c 1}=14.775 \mathrm{GHz}\right.$ and $f_{c 2}=$ $15.225 \mathrm{GHz}$ ) and $0.01 \mathrm{~dB}$ of ripple. For that, Rogers $4003 \mathrm{C}$ 


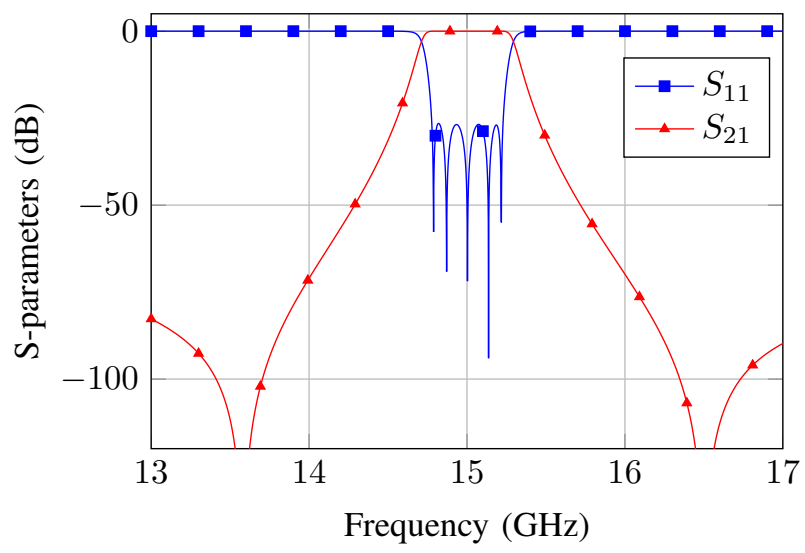

Fig. 7. Simulation results for the $15 \mathrm{GHz}$ filter.

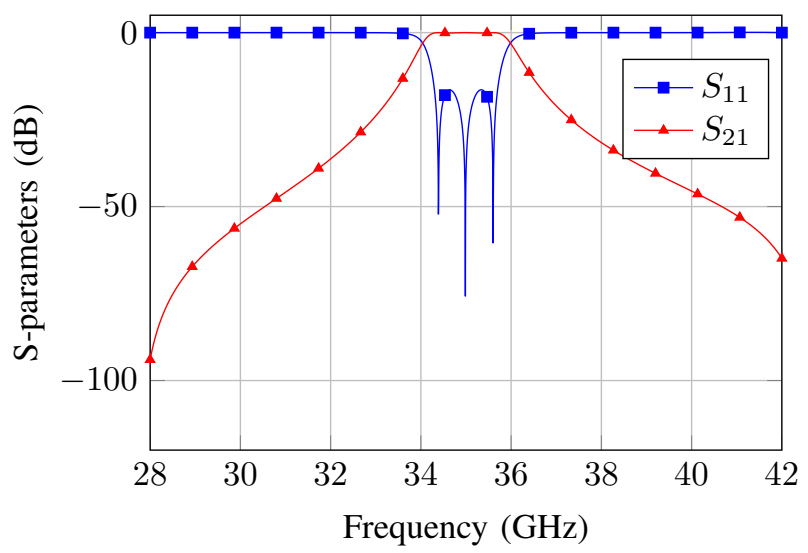

Fig. 8. Simulation results for the $35 \mathrm{GHz}$ and 3 cavities filter.

substrate has been used, with $0.813 \mathrm{~mm}$ thickness, $\epsilon_{r}=3.55$, 26.5 microns of metallization (original plus galvanic) and soldering layers of 5 microns thickness. Fig. 10 shows both, the manufactured filter and a vertical cut of it, where the final aspect of resonators and inverters can be seen, together with the used multilayer transition [20].

The filter manufacture has been done layer by layer. The first layer is the bottom cover, the next corresponds to the input and output lines including the microstrip-to-ESIW transitions (which allow the connection between the filter and the vector network analyzer (VNA) -Anritsu MS4644- [22]), the third layer matches with the first resonator and the corresponding piece of the multilayer transition; and so on, until reaching the top cover that encloses the ESIW (see Fig. 10). All the layers have holes for the aligning screws, which are removed once the tin solder paste is dried.

Figure 11 shows the results obtained after manufacturing the filter and measuring it with the Anritsu VNA, as well as the comparison with the simulated results. Both of these results include the behaviour of the multilayer transition and the microstrip-to-ESIW transition. There is a good agreement between simulation and measurements. Insertion loss is 1.15 $\mathrm{dB}$ and return loss is below $15 \mathrm{~dB}$ in the passband.

To calculate the unloaded quality factor of the filter from measurements, the following equation [23] has been used:

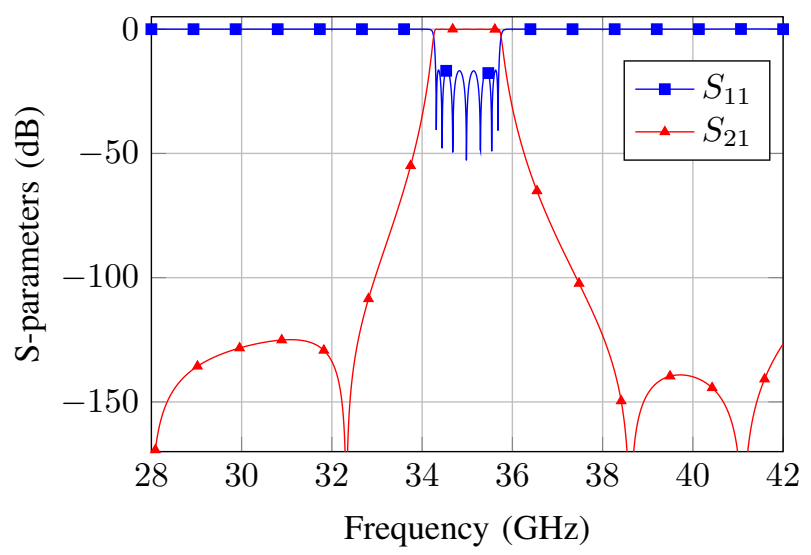

Fig. 9. Simulation results for the $35 \mathrm{GHz}$ and 7 cavities filter.

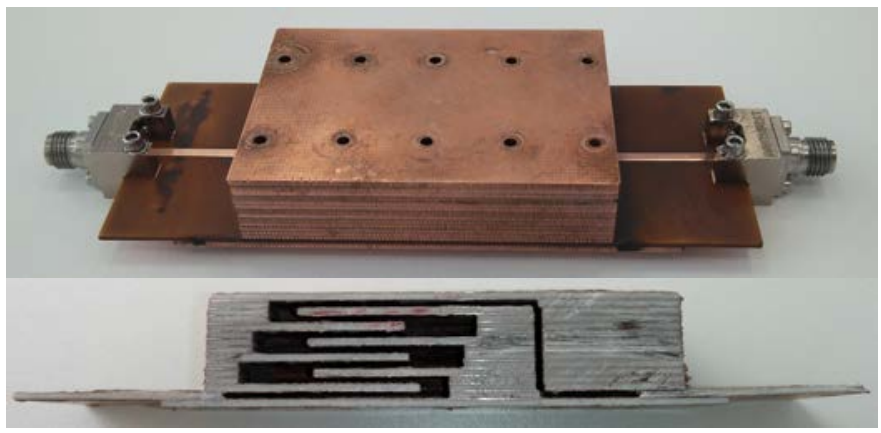

Fig. 10. Manufactured filter (top). Vertical cut of the filter (bottom).

$$
Q_{u}=4.343 \sum_{i=1}^{N} \frac{\Omega_{C}}{F_{B} \Delta L_{A 0}} g_{i} \mathrm{~dB}
$$

where $\Omega_{C}=1$ for a Chebyshev filter, and the coefficients of the lowpass filter prototype are $g_{1}=0.7563, g_{2}=1.3049$, $g_{3}=1.5773, g_{4}=g_{2}, g_{5}=g_{1} . N$ is 5 and $F_{B}$ is $3 \%$. Finally, $\Delta L_{A 0}$ is the increase in losses at the central frequency, when compared to the ideal lossless filter $(0 \mathrm{~dB}$ for this Chebyshev filter). In this case, $\Delta L_{A 0}=0.85 \mathrm{~dB}$, where losses of both microstrip-to-ESIW transitions $(0.3 \mathrm{~dB})$

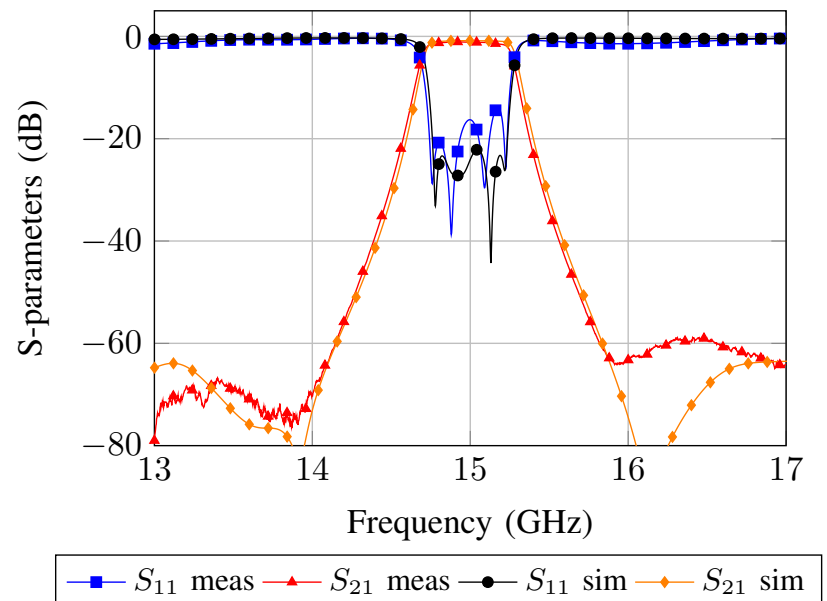

Fig. 11. Results obtained for the manufactured filter. 
have been discounted. With these data the measured unloaded quality factor is 1338 .

If the quality factor is compared with that of similar singlelayer filters in ESIW [2] $(Q=1246(11 \mathrm{GHz})$ and $Q=1358$ $(19.5 \mathrm{GHz})$ ), manufactured with Rogers $4003 \mathrm{C}$ of $1.524 \mathrm{~mm}$ thickness, it is observed that they are very similar, although the quality factor of the single-layer filter should be much higher, as it is manufactured with a thicker substrate. This is explained because resonators of the multilayer filter are of length $\lambda_{g}$ and those of the single-layer filter are of length $\lambda_{g} / 2$.

\section{CONCLUSION}

This paper presents a multilayer ESIW filter built through stacked resonators joined by inverters implemented with Eplane bends of $180^{\circ}$. This filter maintains (or even improves) the good features of equivalent single-layer filters, but increasing compactness, mechanical resistance, and quality factor of resonators

The filter design is based on the traditional approach of concatenating resonators and inverters; it has been necessary to optimize the lengths of the bends in order to obtain the inversion constants of the prototype, and to calculate the proper length of the waveguides that implement the resonators in order to compensate the phase-loading effects introduced by the bends when compared to ideal inverters.

This kind of inverters exhibit an interesting property. They allow the introduction of transmission zeros below and above the passband, which leads to a much more selective response.

Four filters with different characteristics have been simulated to validate the design procedure of this new kind of filters, achieving all of them very good performance. Besides, a 5th-order filter at $15 \mathrm{GHz}$ has been successfully manufactured and measured; its insertion loss is approximately $1.15 \mathrm{~dB}$ at the central frequency and return loss is above $15 \mathrm{~dB}$ in all the passband. The quality factor of this filter is greater than for the same filter implemented in a single layer, due to the fact that the resonators of the multilayer filter are of type $\lambda_{g}$ and the single-layer ones are of type $\lambda_{g} / 2$, obtaining then a quality factor of more than 1300 for this filter.

Furthermore, the compactness degree of this filter is 2.5 times of that of the equivalent in-line filter with 1 storder resonators, or 5 times if the same quality factor is to be achieved with the equivalent in-line filter.

This novel topology allows filter compactness in ESIW. This fact, together with the multilayer ESIW transition described in [20], set the initial point for the design and manufacture of multilayer devices in ESIW.

\section{REFERENCES}

[1] D. Deslandes and $\mathrm{K}$. Wu, "Integrated microstrip and rectangular waveguide in planar form," IEEE Microwave and Wireless Components Letters, vol. 11, no. 2, pp. 68-70, 2001.

[2] A. Belenguer, H. Esteban, and V. Boria, "Novel empty substrate integrated waveguide for high-performance microwave integrated circuits," Microwave Theory and Techniques, IEEE Transactions on, vol. 62, no. 4, pp. 832-839, April 2014.

[3] F. Parment, A. Ghiotto, T. P. Vuong, J. M. Duchamp, and K. Wu, "Air-filled substrate integrated waveguide for low-loss and high powerhandling millimeter-wave substrate integrated circuits," IEEE Transactions on Microwave Theory and Techniques, vol. 63, no. 4, pp. 1228 1238, April 2015.
[4] J. A. Ballesteros, E. Diaz-Caballero, M. D. Fernandez, H. Esteban, A. Belenguer, and V. E. Boria, "Performance comparison of a fourpole folded filter realized with standard and empty substrate integrated waveguide technologies," in Microwave Conference (EuMC), 2017 47th European. IEEE, 2017.

[5] M. D. Fernandez, J. A. Ballesteros, and A. Belenguer, "Design of a hybrid directional coupler in empty substrate integrated waveguide (ESIW)," IEEE Microwave and Wireless Components Letters, vol. 25, no. 12, pp. 796-798, 2015.

[6] E. Miralles, A. Belenguer, H. Esteban, and V. E. Boria, "Cross-guide moreno directional coupler in empty substrate integrated waveguide," Radio Science, vol. 52, no. 5, pp. 597-603, 2017.

[7] J. Mateo, A. M. Torres, A. Belenguer, and A. L. Borja, "Highly efficient and well-matched empty substrate integrated waveguide h-plane horn antenna," IEEE Antennas and Wireless Propagation Letters, vol. 15, pp. 1510-1513, 2016.

[8] M. D. Fernández Berlanga, J. A. Ballesteros Garrido, L. Martínez Cano, H. Esteban González, and Á. Belenguer Martínez, "Thru-reflect-line calibration for empty substrate integrated waveguide with microstrip transitions," Electronics Letters, vol. 51, no. 16, pp. 1274-1276, 2015.

[9] T. Djerafi and K. Wu, "Multilayer integration and packaging on substrate integrated waveguide for next generation wireless applications," in Microwave Conference (EuMC), 2016 46th European. IEEE, 2016, pp. $858-861$.

[10] Z. C. Hao, W. Hong, X. P. Chen, J. X. Chen, K. Wu, and T. J. Cui, "Multilayered substrate integrated waveguide (MSIW) elliptic filter," IEEE Microwave and Wireless Components Letters, vol. 15, no. 2, pp. 95-97, 2005.

[11] Q.-F. Wei, Z.-F. Li, L.-S. Wu, W.-Y. Yin, J.-F. Mao, and L. Li, “Compact cross-coupled circular cavity filters using multilayer substrate integrated waveguide," Electronics letters, vol. 45, no. 6, pp. 314-316, 2009.

[12] T. Djerafi and K.Wu, "Multi-layered substrate integrated waveguide butler matrix for millimeter-wave systems," International Journal of RF and Microwave Computer-Aided Engineering, vol. 22, no. 3, pp. 336$344,2012$.

[13] P. Mohammadi and S. Demir, "Multi-layer substrate integrated waveguide E-plane power divider," Progress In Electromagnetics Research C, vol. 30, pp. 159-172, 2012.

[14] H. Abuzaid, A. Doghri, K. Wu, and A. Shamim, "SIW based multilayer transition and power divider in LTCC technology," in Microwave Symposium Digest (IMS), 2013 IEEE MTT-S International. IEEE, 2013 pp. 1-3.

[15] Z. Zhang, Y. Fan, Y. Cheng, and Y. Zhang, "A novel multilayer dual-mode substrate integrated circular cavity (SICC) filter with two arc-shaped coupling slots," in Electromagnetics Research Symposium Proceedings, 2011, pp. 505-509.

[16] J. Hui, W. Feng, and W. Che, "Balun bandpass filter based on multilayer substrate integrated waveguide power divider," Electronics Letters, vol. 48, no. 10 , pp. 571-573, 2012.

[17] B. Muneer, Z. Qi, and X. Shanjia, "A broadband tunable multilayer substrate integrated waveguide phase shifter," IEEE Microwave and Wireless Components Letters, vol. 25, no. 4, pp. 220-222, 2015.

[18] T. Djerafi, N. Ghassemi, O. Kramer, B. Youzkatli-EI-Khatib, A. B. Guntupalli, and $\mathrm{K}$. Wu, "Small footprint multilayered millimeter-wave antennas and feeding networks for multi-dimensional scanning and highdensity integrated systems," Radioengineering, vol. 21, no. 4, p. 935 , 2012.

[19] J. V. Morro, A. Rodríguez, A. Belenguer, H. Esteban, and V. E. Boria, "Multilevel transition in empty substrate integrated waveguide," Electronics Letters, vol. 52, no. 18, pp. 1543-1544, 2016.

[20] J. A. Ballesteros, M. D. Fernandez, A. Belenguer, H. Esteban, and V. E. Boria, "Versatile transition for multilayer compact devices in empty substrate integrated waveguide," IEEE Microwave and Wireless Components Letters (in review), 2017.

[21] G. L. Matthaei, L. Young, and E. M. T. Jones, Microwave Filters, Impedance-Matching Networks, and Coupling Structures. McGrawHill, 1964.

[22] H. Esteban, A. Belenguer, J. R. Sanchez, C. Bachiller, and V. E. Boria, "Improved low reflection transition from microstrip line to empty substrate-integrated waveguide," IEEE Microwave and Wireless Components Letters, vol. 27, no. 8, pp. 685-687, Aug 2017.

[23] J. S. Hong and M. J. Lancaster, Microstrip filters for RF/microwave applications. John Wiley \& Sons, 2004, vol. 167. 


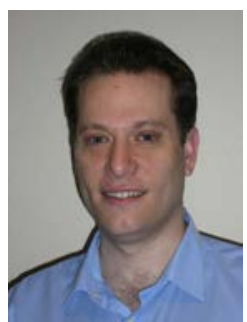

Angel Belenguer (M'04-SM'14) received his degree in telecommunications engineering from the Universidad Politécnica de Valencia (UPV), Spain, in 2000, and his Ph.D. degree, also from the UPV, in 2009. He joined the Universidad de Castilla-La Mancha in 2000, where he is now Profesor Titular de Universidad in the Departamento de Ingenieria Electrica, Electronica, Automatica y Comunicaciones. He has authored or co-authored more than 50 papers in peer-reviewed international journals and conference proceedings and frequently acts as a reviewer for several international technical publications. His research interests include methods in the frequency domain for the full-wave analysis of open-space and guided multiple scattering problems, the application of accelerated solvers or solving strategies (like grouping) to new problems or structures, EM metamaterials, and Substrate Integrated Waveguide (SIW) devices and their applications.

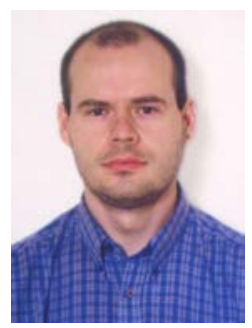

Marcos Fernandez received his degree in telecommunications engineering from the Universidad Politècnica de Catalunya (UPC), Spain, in 1996, and his $\mathrm{Ph} . \mathrm{D}$. degree, from the Universidad Politécnica de Madrid (UPM), in 2006. He joined the Universidad de Castilla-La Mancha in 2000, where he is now Profesor Titular de Universidad in the Departamento de Ingeniería Eléctrica, Electrónica, Automática y Comunicaciones. He has authored or co-authored several papers in peer-reviewed international journals and conference proceedings. His research interests are involved with Empty Substrate Integrated Waveguide (ESIW) devices and their manufacturing and applications.

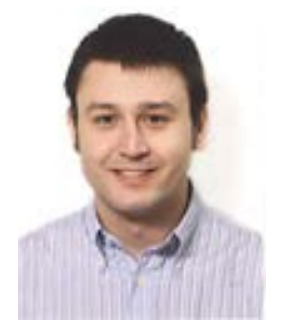

José A. Ballesteros received his degree in telecommunications engineering from the Universidad de Alcalá de Henares (UAH), Spain, in 2009, and his $\mathrm{Ph} . \mathrm{D}$. degree, from the Universidad Politécnica de Madrid (UPM), in 2014. He joined the Universidad de Castilla-La Mancha in 2007, where he is now Lecturer in the Departamento de Ingeniería Eléctrica, Electrónica, Automática y Comunicaciones. He has authored or co-authored several papers in peer-reviewed international journals and conference proceedings. His research interests are involved with Empty Substrate Integrated Waveguide (ESIW) devices and their manufacturing and applications.

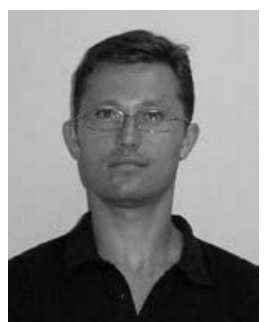

Héctor Esteban González (S'03-M'99-SM'14) received a degree in telecommunications engineering from the Universidad Politécnica de Valencia (UPV), Spain, in 1996, and a Ph.D. degree in 2002. He worked with the Joint Research Centre, European Commission, Ispra, Italy. In 1997, he was with the European Topic Centre on Soil (European Environment Agency). He rejoined the UPV in 1998. His research interests include methods for the full- wave analysis of open-space and guided multiple scattering problems, CAD design of microwave devices, electromagnetic characterization of dielectric and magnetic bodies, and the acceleration of electromagnetic analysis methods using the wavelets and the FMM.

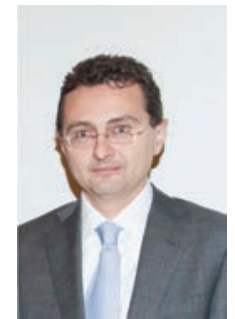

Vicente E. Boria (S'91-A'99-SM'02) was born in Valencia, Spain, on May 18, 1970. He received his Ingeniero de Telecomunicación degree (with firstclass honors) and the Doctor Ingeniero de Telecomunicación degree from the Universidad Politécnica de Valencia, Valencia, Spain, in 1993 and 1997, respectively. In 1993 he joined the Departamento de Comunicaciones, Universidad Politécnica de Valencia, where he has been Full Professor since 2003 In 1995 and 1996, he was holding a Spanish Trainee position with the European Space Research and Technology Centre, European Space Agency (ESTEC-ESA), Noordwijk, The Netherlands, where he was involved in the area of EM analysis and design of passive waveguide devices. He has authored or co-authored 7 chapters in technical textbooks, 75 papers in refereed international technical journals, and over 150 papers in international conference proceedings. His current research interests are focused on the analysis and automated design of passive components, left-handed and periodic structures, as well as on the simulation and measurement of power effects in passive waveguide systems. Dr. Boria has been a member of the IEEE Microwave Theory and Techniques Society (IEEE MTT-S) and the IEEE Antennas and Propagation Society (IEEE AP-S) since 1992. He is member of the Editorial Boards of the IEEE Transactions on Microwave Theory and Techniques, IEEE Microwave and Wireless Components Letters, Proceeding of the IET (Microwaves, Antennas and Propagation), IET Electronics Letters and Radio Science. Since 2013, he serves as Associate Editor of IEEE Microwave and Wireless Components Letters. He is also a member of the Technical Committees of the IEEEMTT International Microwave Symposium and of the European Microwave Conference.

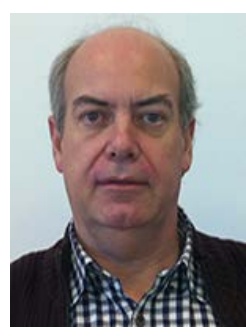

Juan J. de Dios received the Ingeniero de Telecomunicación degree in 1991 and the Doctor Ingeniero de Telecomunicación degree ( $\mathrm{PhD}$ in Communications) summa cum laude in 2004 from the E.T.S. Ingenieros de Telecomunicación of the Universidad Politécnica de Madrid (Spain). He was working for Lucent Technologies (formerly AT\&T) at the Transmission Engineering Lab (Bell Labs) in Madrid (Spain) from 1991 to 1999. Since 1999 he is with the E. Politécnica de Cuenca of the Universidad de Castilla-La Mancha (Spain), where he is now Profesor Titular de Universidad in the Departamento de Ingeniería Eléctrica, Electrónica, Automática y Comunicaciones. His research interests include image and video processing, RFID, microwave circuits and antennas, SIW devices analysis and their applications. 